\title{
ASSISTÊNCIA DE ENFERMAGEM E AS SEQÜELAS NEUROLÓGICAS DO SARAMPO
}

\author{
Magda Andrade Rezende*
}

REZENDE, M. A. Assistência de enfermagem e as seqüelas neurológicas do sarampo. Rev.Esc.Enf.USP., São Paulo, 23(2):-, ago. 1989.

As seqüelas neurologicas do sarampo podem ocorrer como conseqüência de encefalites ou constituir o quadro chamado pan-encefalite esclerosante sub-aguda (PEESA).

As encefalites sâo letais em cerca de 15 a $18 \%$ dos casos, causando danos permanentes (motores elou mentais) em aproximadamente $25 \%$ dos pacientes. $A$ PEESA é sempre letal.

Enfatiza-se as conseqüências sociais e econômicas destes problemas.

Sugere-se assistência de enfermagem de acordo com os niveis de prevenção de Leavell \& Clark.

UNITERMOS: Assistência de Enfermagem. Sarampo.

\section{INTRODUÇĀO}

Nosso país tem o grave problema de apresentar incidência elevada de doenças preveníveis, dentre as quais avulta o sarampo.

Em nosso meio é doença de extrema gravidade, podendo acarretar graves complicaçōes e seqüelas.

Citam-se como complicaçōes do sarampo: broncopneumonia, encefalite, diarréia, laringotraqueobronquite, etc, podendo inclusive levar à óbito ${ }^{11}$.

As complicações neurológicas, temporárias ou permanentes, podem ser incapacitantes.

Este trabalho se deterá nas seqüelas neurológicas.

Optou-se por chamar a atenção sobre este ponto porque:

(1) as seqüelas neurológicas ocorrem independentemente da classe social do acometido, isto é, não estão relacionadas com o seu estado nutricional ${ }^{16}$.

\footnotetext{
* Auxiliar de ensino da Disciplina de Enfermagem-Pediátrica da Escola de Enfermagem da USP. Aluna do curso de mestrado em Enfermagem Pediátrica e Pediatria Social da Disciplina de Enfermagem da Escola Paulista de Medicina.
} 
(2) Algumas sāo incapacitantes e permanentes ${ }^{13,17}$, portanto, o déficit físico e mental do indivíduo deve ser levado em conta.

(3) Podem ser de prognóstico fechado ${ }^{5,17}$.

(4) A doença é prevenível por imunização (*).

A assistência que deve ser prestada ao indivíduo sadio e ao doente pode ser didaticamente analisada pelo esquema proposto por LEAVELL \& CLARK ${ }^{8}$ : prevençāo primária, secundária e terciária.

Em qualquer destas a atuação da enfermeira pode ser fundamental, entretanto, a primária deve se destacar quanto aos esforços a ela dispensados: além de evitar maior sofrimento, a relação custo/benefício o justifica.

\section{ASPECTOS CLÍNICOS E EPIDEMIOLÓGICOS DAS SEQÜELAS NEURO- LÓGICAS}

Pode-se classificá-las como sendo de dois grandes tipos 5,13,16:

(1) síndromes encefalopáticas em geral; $e$,

(2) pan-encefalite esclerosante sub-aguda (PEESA).

Os dados sobre incidência das síndromes encefalopáticas, e até mesmo quanto a critério de diagnóstico ${ }^{16}$ variam de acordo com o autor consultado.

Isto se deve possivelmente à dificuldade de distinguir se o processo se deve ao próprio sarampo ou outra causa clínica associada, como, por exemplo, desidrataçāo ou anoxia ${ }^{16}$.

Entretanto, clínica compatível com encefalomielite costuma atingir 0,35 indivíduos em cada 100 acometidos pelo sarampo ${ }^{16}$. Estes dados sāo inferiores aos apontados em anos anteriores ( 1 a 1,5 por 1000$)^{16}$.

O quadro clínico surge por volta do quinto dia do exantema, embora isto possa ser bastante variável ${ }^{5,13}$. Caracteriza-se por torpor, irritabilidade, febre, sinais meníngeos, cefaléia, vômitos ${ }^{5}$. Pode evoluir para convulsōes e coma em poucas horas 5 .

Pode haver comprometimento motor (plegia, espasticidade, hipotonia), ou mental, e ainda, alteração de comportamento ou síndrome convulsiva ${ }^{13}$.

Cerca de $25 \%$ das crianças que desenvolvem quadro de encefalite permanecem com seqüelas ${ }^{13}$. A letalidade oscila em torno de 15 a $18 \%{ }^{13,16}$.

A PEESA era anteriormente conhecida como encefalite de Dawson ou leucoencefalite de Van Bogaert ${ }^{9}$.

É uma doença degenerativa, progressiva, cujo curso já é conhecido 5,17

(*) Deve-se levar em conta que a eficácia da vacina é de cerca de $98 \%$, caso tenham sido obedecidas as suas necessidades de acondicionamento e aplicaçãol4. 
Há deterioraçao intelectual gradual sem alteraçāo da personalidade, seguida de comprometimento motor (abalos micclônicos, incoordenação, convulsōes), cegueira, decorticação, coma e morte 5,17. (Acompanhamento de 31 pacientes por CANELAS ${ }^{4}$, quando ainda era desconhecida a etiologia da doença, demonstrou que o primeiro sintoma clínico que surgiu foi alteração psiquiátrica, presente em $55,6 \%$ dos casos).

Segundo DIAMENT ${ }^{5}$ e SEVER ${ }^{17}$ a evolução da PEESA é sempre fatal, OSELKA $^{13}$ faz a ressalva que pode haver anos de remissāo.

A maioria dos pacientes sobrevive de 12 a 18 meses após o diagnóstico ${ }^{5,17}$.

Apesar de ser conhecido o agente, o vírus do sarampo, ainda não se conhece a patogenia e não há tratamento eficaz ${ }^{5,17}$.

Trabalho realizado nos EUA, com 200 pacientes, demonstrou uma incidência de um caso de PEESA em cada um milhão de habitantes, sendo que na região sudeste havia uma incidência 4 a 5 vezes maior ${ }^{17}$.

Outro estudo, feito no mesmo país demonstrou uma incidència de 0,35 por um milhão de habitantes (entre 1960 e 1976) ${ }^{10}$. Trabalho realizado na França acusou a incidência de 0,38 casos por um milhão de habitantes 16 , chamando a atençào para a variabilidade regional destes dados: no Libano, por exemplo, é bem maior ${ }^{16}$.

Alguns fatos parece que sāo comuns aos pacientes com PEESA:

- infecção por sarampo em tenra idade ${ }^{10,17}$;

- infecção simultânea por outro vírus ${ }^{17}$;

- exposição a pássaros, em geral domésticos ${ }^{17}$. O início da moléstia pode coincidir com uma epizootia ${ }^{4}$.

- meio-ambiente rural ${ }^{17}$. (Na revisăo teita no Brasil ${ }^{4}$ o mesmo fato foi encontrado).

- lesōes cefálicas após a ocorrência do sarampo ${ }^{17}$.

- predominância evidente do sexo masculino $0^{4,10,13}$.

- maior incidência em brancos ${ }^{4,10,17}$. Segundo MODLIN ${ }^{10}$ ainda nāo está bem determinado até que ponto isto se deve a um fator étnico realmente, podendo ser na verdade econômico. Deve-se ter mente que este autor se refere a dados encontrados na região sudeste dos EUA (Mississipi).

O período de latência da moléstia costuma ser grande: aproximadamente 7 anos $^{17}$, e não se tem certeza acerca dos motivos desencadeadores dos sintomas ${ }^{17}$. Como a maior parte dos pacientes está entre 13 e 19 anos $^{4,17}$, por ocasião do diagnóstico, talvez as mudanças puberais estejam ligadas au desencadeamento dos sintomas $^{17}$.

São encontrados níveis elevados e anticorpos no soro e no líquor ${ }^{13,17}$, por 
ocasiāo do diagnóstico da PEESA. Possivelmente porque, por meses e anos, células morrem e descarregam antígenos víricos na corrente sangüínea ${ }^{17}$.

\section{INCIDÊNCIA}

A incidência de encefalite e de PEESA deve ser calculada a partir do número de ocorrências de sarampo, o que acarreta muitas dificuldades extras, além do próprio diagnóstico da complicação (em nosso país).

No caso da encefalite é preciso distinguir se a mesma ocorre pelo sarampo ou por causa associada.

Quanto à PEESA, sabe-se que individuos acometidos tiveram sarampo clínico cerca de 7 anos antes.

É importante a tomada da história, a qual é confirmada por sorologia no sangue e líquor ${ }^{5,13,17}$. No Brasil, exames sorológicos sāo caros e difíceis de se fazer em instituiçōes públicas, sendo esta uma dificuldade a mais.

Considerando nossos baixos índices de vacinaçāo e elevada incidência de sarampo é de supor que a ocorrência de encefalite e PEESA sejam elevadas.

No ano de 1983, 4,8\% das crianças de 1 a 4 anos acometidas por disfunçōes tiveram como causa das mesmas o sarampo ${ }^{12}$, tendo sido a quinta causa de seqüelas. A quarta foi desnutrição $(7,7 \%)$. Sarampo e desnutrição são uma dupla arrasadora na infância, especialmente se juntas ${ }^{11}$ e não podemos esquecer que sarampo é doença sub-notificada.

\section{ASPECTOS SOCIAIS}

Sabe-se que grande parte da nossa população tem rendimento menor ou igual ao salário mínimo, o qual atualmente não cobre as despesas para as quais foi calculado em 1940'. Também é fato conhecido que esta grande camada da população, que aufere baixos rendimentos, tem baixa escolaridade e vacina seus fillhos com maior dificuldade: geralmente mora em regiāo periférica, a qual dispõe de escassos recursos de saúde; necessita usar vários meios de transporte para chegar à unidade básica de saúde mais próxima ${ }^{6,7}$ e tem pouca, ou nenhuma informaçāo sobre a importância da vacinaçāo.

Além disso, a baixíssima renda impossibilita nutriçāo adequada. As crianças säo as que mais sofrem as consequiências ${ }^{18}$.

Isto faz com que as crianças de tais familias tenham uma taxa de imunizaçāo menor do que a das classes abastadas ${ }^{6,7}$. podemos ver como exemplo as taxas de vacinação da região sul da cidade de São Paulo (região de Santo Amaro), as quais são mais baixas do que as do restante da cidade. A região é sabidamente muito 
pobre, com população constituída basicamente por migrantes nordestinos (*).

No país a cobertura vacinal contra o sarampo é também variada, refletindo as condiçōes sócio-econômicas de cada uma das regiōes: $48,6 \%$ na regiāo norte; $51 \%$ na nordeste; $84,4 \%$ na sudeste; $84,4 \%$ na sul e $58,4 \%$ na centro-oeste. (Dados de 1983, cobertura de crianças de menos de um ano de idade) $)^{15}$.

Ocorre que a criança desta população, já desnutrida, ao contrair sarampo, provavelmente terá complicações ${ }^{11}$, as quais freqüentemente serão pulmonares ${ }^{13} \mathrm{e}$ não raramente desfecharāo em óbito ${ }^{11}$.

A encefalite e a PEESA, diferentemente, acometem crianças de qualquer condição nutricional ${ }^{16}$. Seja qual for o estrato do indivíduo acometido, haverá sofrimento. Além disso o fator econômico é variável importante, alterando sua condição de arcar com os custos do tratamento, o qual muitas vezes é paliativo.

Segundo dados da APAE (Associação dos Pais e Amigos dos Excepcionais) de São Paulo, o custo operacional de uma criança com deficiência mental atendida pela instituiçāo, em regime de atendimento/dia, custa aproximadamente US\$1.500 por ano(**).

O custo da vacina contra sarampo é menor do que um dólar (Laboratorio Aché, em 19-7-88, Cz\$ 198,80).

Segundo a mesma instituição, no ano de 1985 , foram atendidas na instituição 6 crianças, cuja causa da deficiência mental fôra sarampo.

Acredito, entretanto, que o número de crianças com deficiêricia mental e/ou motora decorrente de sarampo deve ser bem maior pelos seguintes motivos:

(1) As 6 crianças atendidas em 1985 representaram 0,54\% de toda a demanda atendida (1091 indivíduos), a qual, por sua vez, havia sido triada a partir de aproximadamente o dobro de candidatos. Suponho que grande parte da demanda não pode ser atendida por morar em local muito distante, ou por nāo dispor de alguém que acompanhasse o cliente à instituição diariamente, arcando inclusive com o custo do transporte.

Estas suposiçōes nāo sāo infundadas, uma vez que no ano de 1986, a instituição não pôde atender $16,86 \%$ da demanda devida à residência distante; e

(*) Dados dos Boletins de Produçăo do SUDS - Regional 8 (Santo Amaro) demonstram que a cobertura vacinal de crianças de 0 a 1 ano de idade, naquela região, contra o sarampo foram: em 1983, 82,28\%; em $198470,78 \%$; em 1985 72,89\%; em 1986, 75\%, e, em 1987,65,23\%. A pós campanha a cobertura vacinal elevou-se, no último ano mencionado, a $91,93 \%$. Ate mesmo a cobertura da vacina Sabin muito fácil de ser administrada, foi baixa no ano de 1987: 59,77\%, o menor valor da série desde o ano de 1983. Este também foi aumentado após campanha vacinal, chegando a $67 \%$.

(**) Dados fornecidos pelo médico-supervisor do Centro de Habilitaçăo da APAE/SP. Francisco Assumpção Jr. 
13,89\% devido a problema familiar (falta de companhante e de condiçōes de pagar o transporte) (*).

(2) A APAE/SP nāo atende individuos que apresentam exclusivamente dificiència motora, a qual pode ser uma das seqũelas do sarampo.

(3) A instituição é ponto de referência para atendimento de crianças com fenil-cetonuria, supondo-se que atenda praticamente todos os acometidos por essa doença $\left(^{*}\right)$. Ora, em 1985 foram atendidas 7 crianças portadoras de fenil-cetonúria ( $0,63 \%$ da demanda atendida). Chama a atençāin, ao se comparar estes dados com os do sarampo o quanto este último deve estar sub-representado na demanda atendida, sabendo-se quão elevada é sua incidência. (Segundo o ANUÁRIO ESTATÍSTICO DO BRASIL $1986^{3}$, foram notificados 116.781 casos de sarampo no Brasil naquele ano, dado esse que é sabidamente sub-notificado. A incidência da doença, segundo a mesma fonte, aumentou de 31 por 100.000 habitantes e em 1982 para 84,3 em 1986. Mesmo que se leve em conta que o sarampo assume proporçōes epidêmicas a cada 2 ou 3 anos, e que, em 1984, houve aumento nas Américas, países como EUA e Canadá que tem uma excelente cobertura vacinal saíram indenes ${ }^{12}$ ).

(4) Já pude observar muitas vezes, em familias do estrato social e econômico mais baixo, que muitas deficiências mentais ou motoras são encaradas como aceitáveis, como desígnio divino, não implicando em procura de recursos para minimizá-las. Não se deve perder de vista que esta deve ser a populaçāo que tem, possivelmente a maior incidência de sarampo, porque vacinam muito menos do que os estratos melhor aquinhoados. Tem provavelmente, portanto, maior incidência de complicações e seqüelas não tratadas, além de desconhecidas em sua magnitude.

(5) E, finalmente, não podemos esquecer que tanto as encefalites quanto a PEESA podem ser mortais, aquelas a curto ou longo prazo e estas a longo. Só foram atendidas pela APAE/SP crianças com danos causados por encefalites, tendose que descartar as que já haviam falecido durante a hospitalização devido às seqüelas. Não foram atendidas crianças portadoras de PEESA:

Esta série de motivos faz supor que as 6 crianças atendidas são minúscula parcela das que tiveram seqüelas neurológicas pelo sarampo

\section{CONCLUSŌES}

Devemos fazer rotineiramente análise de informaçōes como estas, com vistas à elaboraçāo de planos de assistência. Quanto a esta última julgo proveitoso usar como método a história natural da doença ${ }^{8}$, por ser abrangente e de fácil aplicáção.

No presente caso pode-se fazer o seguinte plano de atuação, que pode ser

(*) Dados fornecidos pelo médico supervisor do Centro de Habilitaçāo da APAE/SP, Francisco Assumpção Jr. 
aumentado, pois não esgota o assunto.

\section{Prevenção Primária}

(Pronução da Saúde e Proteção Específica):

(1) Educação do cliente ou paciente sobre imunização, reaçōes, época adequada de vacinaçăo, etc.

(2) Educação da comunidade: vizinhos, amigos, colegas, etc.

(3) Avaliação da cobertura vacinal.

(4) Elaboraçāo de planos de cobertura vacinal e implantação dos mesmos.

(5) Elaboraçāo de campanhas de divulgação sobre importância da imunização através de meios de comunicação de massa.

(6) Aplicação da imunização. Avaliação das condiçōes de estocagem e administração.

\section{Prevenção Secundária}

(Diagnóstico e Tratamento Precoce, e, Limitaçăo da Invalidez):

(1) Encaminhamento de indivíduo com suspeita da doença para diagnóstico.

(2) Encaminhamento para hospitalização, se necessário: desnutrição grave; acometimento pulmonar ou neurológico.

(3) Prevenção de hospitalismo permitirido a iivre entrada dos pais ou responsáveis ${ }^{2}$.

\section{Prevençāo Terciária}

(Reabilitaçāo):

(1) Encaminhamento da criança à instituição de doentes mentais e/ou motores, para diagnóstico e tratamento. Se necessário é possível fazer treinamento dos pais ou responsáveis nas atividades de reabilitação da criança.

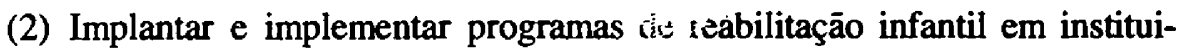
ções de saúde.

(3) Em instituições que trabalham com populaçāo infantil realizar atividades com as crianças (tais como dramatizaçāo) que as levem a sentir empatia pelos portadores de deficièncias. Quanto aos pais e adultos de um modo geral devem ser educados para perceberem tais problemas, após o que poderão tentar resolvê-los ou amenizá-los.

Devemos ter em mente que o sarampo deve ser evitado a qualquer custo, $e$ que isto pode ser feito quer trabalhemos com crianças, com adultos, em atividade preventiva ou curativa. Em cada nivel há açōes específicas que podem ser exercidas. 
REZENDE, M.A. Nursing care and the neurological sequelaes of measles. Rev. Esc. Enf. USP, São Paulo, 23(2): - , Aug. 1989.

The neurological sequelae after measles can be encephalitis or subacute sclerosing pan-encephalitis (SSPE). The encephalitis is lethal in 15-18\% of the patients, that can rest handiccaped at 25\%. The SSPE is always lethal. The social and economical consequences of these problems are emphaised. It is suggested nursing care by Leavell \& Clark levels of prevention.

UNITERMS: Nursing care. Measles.

\section{REFERÊNCIAS BIBLIOGRÁFICAS}

1. ALZUGARAY, D. \& ALZUGARAY, C. Crescimento económico e arrocho salarial. In: - Retrato do Brasil Săo Paulo, Ed. Três, 1984. v.3, p. 157-62.

2. ANGELO, M. Visitas restritas a crianças hospitalizadas: uma barreira para a interaçăo mãe-filho. Rev Esc Enf USP, Sāo Paulo, 17(3): 229-34, 1983.

3. ANUÁRIO ESTATÍSTICO DO BRASIL: 1986, Rio de Janeiro, Fundação Instituto Brasileiro de Geografia e Estatistica, 1987.

4. CANELAS, H.M. et alii. Subacute sclerosing leucoencephalitis: an epidemiological, clinical and biochemical study of 31 cases. Arq Neuropsiquiatr., Săo Paulo, 25(4): 255-68, 1967.

5. DIAMENT, A.J. Neuroviroses. In: MARCONDES, E. Pediatria básica. Sāo Paulo, Sarvier, 1986. v.1, p. 754.

6. GRANT, J. Situação mundial da infáncia 1987. Brasflia, UNICEF, 1987. p. 43.

7. — Situação mundial da infáncia 1988. Braślia, UNICEF, 1988. p. 13,51-3.

8. LEAVELL, H.\& ClaRK, E.G. Medicina preventiva. Sāo Paulo, McGraw-Hill, 1977. p. 17.

9. McDONALD, R. SSPE (subacute sclerosing panencephalitis): is measles vaccination promovite or preventive? Clin. Pediatr., Philadelphia, 16: 124-27, 1977.

10. MODLIN, J.F. et alii. Epidemiology of sub-acute sclerosing panencephalitis. J. Pediatr, St. Louis, 94: 231-36, 1976.

11. MORLEY, D. Pediatria no mundo em desenvolvimento: prioridades. São Paulo, Paulinas, 1980. cap. 12.

12. ORGANIZAÇĀO PANAMERICANA DA SAÚDE. Las condiciones de la salud en las Americas: 1981-1984. Washington, 1986. v.1, p. 60. (Publicação cientifica, 500).

13. OSELKA, G. Doenças exantemáticas. In: MARCONDES, E. Pediatria hásica. São Paulo, Sarvier, 1986 . v.2, p. 884-5.

14. OSELKA, G. et alii. Higiene anti-infecciosa. In: MARCONDES, E. Pediatria básica. São Paulo, Sarvier, 1986. v.1, p. 126.

15. PANAMERICAN HEALTH ORGANIZATION, Health conditions in the Americas: 1981-1984. Washington, 1986. v.2, p. 57-9 (Publicaçāo científica, 500).

16. REY, M. et alii. Situación del sarampión en Francia. In: KATZ, S.L. et alii. Simposio internacional sobre inmunización contra el sarampión. Washington, Organizaçāo Panamericana da Saúde, 1985. p. 55-63.

17. SEVER, J.L. Infección sarampiosa persistente del sistema nervioso central: panencefalitis esclerosante subaguda. In: KATZ, S.L. et alii. Simposio internacional Inmunización contra el Sarampion. Washington, Organização Panamericana da Saúde/Organizaçăo Mundial da Saúde, 1985. p. 101-10.

18. UNICEF. Impacto da recessão sobre as crianşas: estudo especial do UNICEF. Brasília, UNICEF, 1984. 32p. 